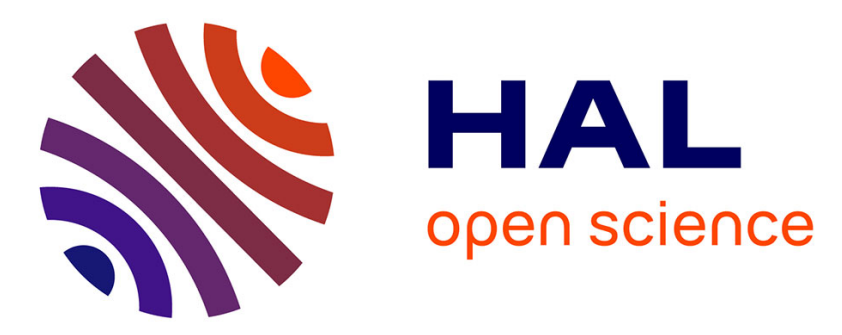

\title{
Changes in pore characteristics with depth for structural crusts
}

\author{
Dennis Fox, R B Bryan, C A Fox
}

\section{To cite this version:}

Dennis Fox, R B Bryan, C A Fox. Changes in pore characteristics with depth for structural crusts.

Geoderma, 2004, 10.1016/j.geoderma.2003.08.010 . hal-02572275

\section{HAL Id: hal-02572275 \\ https://hal.science/hal-02572275}

Submitted on 6 Dec 2021

HAL is a multi-disciplinary open access archive for the deposit and dissemination of scientific research documents, whether they are published or not. The documents may come from teaching and research institutions in France or abroad, or from public or private research centers.
L'archive ouverte pluridisciplinaire HAL, est destinée au dépôt et à la diffusion de documents scientifiques de niveau recherche, publiés ou non, émanant des établissements d'enseignement et de recherche français ou étrangers, des laboratoires publics ou privés. 


\title{
Changes in pore characteristics with depth for structural crusts
}

\author{
D.M. Fox ${ }^{\mathrm{a}, *}$, R.B. Bryan ${ }^{\mathrm{b}}$, C.A. Fox ${ }^{\mathrm{c}}$ \\ ${ }^{\text {a } U M R ~} 6012$ CNRS, Geography, University of Nice, 98 Blvd. Ed. Herriot, B.P. 3209, 06204 Nice cedex 3, France \\ ${ }^{\mathrm{b}}$ Faculty of Forestry, University of Toronto, 33, Willcocks St., Toronto, ON, Canada M5S 3B3 \\ ${ }^{\mathrm{c}}$ Greenhouse and Processing Crops Research Centre, Agriculture and Agri-Food Canada, Harrow, ON, Canada NOR $1 G O$
}

Received 17 September 2002; received in revised form 22 July 2003; accepted 29 August 2003

\begin{abstract}
Micromorphological techniques have frequently been used to describe processes leading to surface crusting. Image analysis can be helpful in quantifying changes in porosity necessary for estimating hydraulic parameters in crust infiltration models. The objective of this study was to quantify changes in pore area and frequency for three pore shapes (round, irregular, and elongate) and four size classes $(50-200,200-350,350-500$, and $>500 \mu \mathrm{m})$. Porosity decreased exponentially as the surface was approached from a depth of about $10 \mathrm{~mm}$. The number of pores was roughly inversely proportional to pore area as larger pores were fragmented into numerous small pores. Intermediate-sized $(350-500 \mu \mathrm{m})$ elongate pores were the most sensitive to crusting processes, and these were divided into small $(50-200 \mu \mathrm{m})$ and small intermediate $(200-350 \mu \mathrm{m})$ round pores. Changes in pore shape and size distribution make estimating crust hydraulic conductivity and thickness extremely difficult, but a thickness of 5 $\mathrm{mm}$ appears to be a reasonable estimate for modelling purposes.
\end{abstract}

(C) 2003 Published by Elsevier B.V.

Keywords: Soil crust; Surface crusting; Soil porosity; Infiltration; Micromorphology

\section{Introduction}

Soil surface crusting controls infiltration into most bare soils and influences both runoff and soil erosion. Predicting amounts of runoff or erosion rates frequently requires a functional infiltration model for surface crusted soils. Several infiltration models have been developed over the past few decades (Hillel and Gardner, 1970; Morin and Benyamini, 1977; Ahuja and Ross, 1983; Brakensiek and Rawls, 1983; Aboujaoudé et al., 1991; Bristow et al., 1995), many of

\footnotetext{
* Corresponding author. Fax: +33-4-93375430.

E-mail addresses: fox@unice.fr (D.M. Fox), r.bryan@utoronto.ca (R.B. Bryan), foxc@em.agr.ca (C.A. Fox).
}

which depend on estimates of the hydraulic properties of the crusts.

Current models of crust formation have largely been derived from observations using various micromorphological techniques: photomicrographs (Duley, 1939; McIntyre, 1958; Evans and Buols, 1968), scanning electron microscope (Chen et al., 1980; Tarchitzky et al., 1984), optical microscope (Beckmann and Smith, 1974; Boiffin and Bresson, 1987; Luk et al., 1990; Collins et al., 1986), image analysis (Pagliai, 1987; Gimenez et al., 1992), and combinations of the above (Valentin, 1991). Most authors interpreted crust sections to describe stages in crust genesis, and they were useful in identifying two broad categories of commonly occurring crusts: structural and sedimenta- 
ry (or depositional). Sedimentary crusts are formed by the deposition of detached sediments and micro-aggregates in surface depressions. Soil compaction under raindrop impact is the dominant process in structural crust formation. Sedimentary crusts are generally of lower hydraulic conductivity than structural crusts (Fox et al., 1998). The soil surface passes from one dominated by structural crusts to one dominated by sedimentary crusts as a function of cumulative rainfall (Bresson and Boiffin, 1990).

The importance of two features other than compaction and aggregate re-organisation has been debated in the literature: The first is the importance of a washedin layer, and the second of a skin seal. The first is formed by the downward migration of fine particles which clog pores beneath the surface. It was initially identified by McIntyre (1958) and subsequently observed by others (Agassi et al., 1985; Onofiok and Singer, 1984; Luk et al., 1990), but not by everyone (Chen et al., 1980; Tarchitzky et al., 1984; Collins et al., 1986). Its absence was attributed to the horizontal removal of finer sediments by water flowing over the surface (West et al., 1992). McIntyre (1958) was also the first to identify a $0.1-\mathrm{mm}$ skin seal composed of closely aligned clay sediments at the surface. However, it seems likely that this skin, deposited after rain, is of no hydraulic significance during the rainfall (Tackett and Pearson, 1965; Farrel, 1972; Bryan, 1973; Pagliai et al., 1983; Onofiok and Singer, 1984; Norton, 1987; Remley and Bradford, 1989; Mualem et al., 1990). A thicker less porous layer observed by Moss (1991) corresponds better to the disrupted layer commonly observed in structural crusts (Chen et al., 1980; Tarchitzky et al., 1984), and this is due to compaction and coalescence of aggregates (Boiffin and Bresson, 1987) under raindrop impact.

The thickness of structural crusts is usually less than about $5 \mathrm{~mm}$, though crusts of up to $20 \mathrm{~mm}$ have been observed (McIntyre, 1958; Tackett and Pearson, 1965; Epstein and Grant, 1967; Farres, 1978; Eigel and Morre, 1983; Collins et al., 1986). Boiffin (1985) and Farres (1978) have related crust thickness to initial aggregate size where larger aggregates form surface crusts more slowly but result in a thicker crust. Other factors, especially aggregate stability, strongly influence the thickness and hydraulic conductivity of crusts (Fox and Le Bissonnais, 1998). However, Mualem et al. (1990) have questioned in a review the notion of two distinct layers, an overlying disrupted layer and underlying untouched layer. They argue that there is no distinct limit between the disrupted layer and underlying soil, and the impact of crusting on soil porosity decreases exponentially from the surface down. This would make modelling infiltration in crusted soils as a two-layer system theoretically awkward since it is difficult to attribute values to a crust thickness which has no distinct limit and to a hydraulic conductivity that varies markedly within a few millimeters. This point will be developed below, but it is worth noting that most of the above studies were based on visual interpretations of thin sections of a thin uppermost layer or impregnated blocks, and there is a need for quantifying changes in porosity that cannot necessarily be detected visually, as noted by Mualem et al. (1990). Some authors (Borselli et al., 1996; Panini et al., 1997; Uson and Poch, 2000) have proceeded in this direction by quantifying changes in pore shape and size before and after rainfall for different surface treatments, but the measurements were bulk values for the entire upper $5-10 \mathrm{~cm}$ of soil. None of the studies quantifying pore type and size distribution to date have attempted to distinguish between the crust layer and underlying soil.

The objective of this paper is to quantify changes in soil porosity with depth in a structural crust. Even though a full three-dimensional model of pore characteristics and connectivity would be needed for quantifying hydraulic parameters directly from pore micromorphology data, the changes in porosity defined at the spatial resolution used below can be useful in estimating the impact of crusting on some hydraulic parameters, and more particularly on crust thickness.

\section{Materials and methods}

\subsection{Rainfall simulations}

The experiment described here was part of a larger study of the impact of slope angle on surface crusting and interrill erosion, and experimental details have been given elsewhere (Fox et al., 1997; Fox and Bryan, 1999). The soil is described as the Pontypool sandy loam (50\% sand, $22 \%$ silt, and $28 \%$ clay), a grey brown Alfisol located in Southern Ontario, Canada. Sufficient soil was air-dried to a moisture content of 
about $8 \%$ and passed through a $4.0-\mathrm{mm}$ sieve. For each rainfall simulation, soil was packed in 2.0 -cm layers in a $100 \mathrm{~cm}$ length $\times 40 \mathrm{~cm}$ width $\times 10 \mathrm{~cm}$ depth tray to a mean bulk density of $1.29 \mathrm{~g} \mathrm{~cm}^{-3}$ (st. dev. $=0.03 \mathrm{~g}$ $\mathrm{cm}^{-3}$ ). Each layer was lightly compacted with a board, and the surface was roughened by hand before adding the next layer, as described by Kinnell and Cummings (1993). The tray was then set at one of five slope gradients $2.5 \%, 11.5 \%, 20.5 \%, 30 \%$, and $40 \%$ and subjected to simulated rain using tap water and a sprinkler system similar to that of Poesen et al. (1990). Mean rainfall intensity was $49.1 \mathrm{~mm} \mathrm{~h}^{-1}$ with a range of from 38.2 to $56.3 \mathrm{~mm} \mathrm{~h}^{-1}$ and standard deviation of $4.7 \mathrm{~mm} \mathrm{~h}^{-1}$. In addition to runoff, subseal pressure head was measured at depths of 1,3 , and $5 \mathrm{~cm}$ depths using micro-tensiometers, as described in Fox et al. (1997).

\subsection{Sample preparation for image analysis}

For each slope inclination, samples of the soil were taken for micromorphological examination following the rainfall simulation; six replicates were collected for each slope except for the $20.5 \%$ slope which had seven. The soils were taken using metal Kubiena boxes (7.5 cm length $\times 6.5 \mathrm{~cm}$ width $\times 4.0 \mathrm{~cm}$ depth), carefully wrapped in clear plastic bag with the open top and bottom supported by $1 / 4$ in. plywood lids. The boxes were pushed downward into the soil with the long axis oriented parallel to the slope; paired samples were taken from the centre of the soil tray. One of the samples was air-dried and the other underwent acetone exchange prior to resin impregnation. However, the acetone exchange procedure disrupted the surface crust of several samples, so only the air-dried samples were used. Since the soil had a low clay content and air-drying is typical of conditions in the field, this was considered more representative of natural crusts. Impregnation was carried out under vacuum with a polyester resin according to procedures outlined in Fox et al. (1993).

Upon polymerisation, the hardened blocks were cut using rock saws to prepare a 1.5 -cm-thick block that measured $7.5 \mathrm{~cm}$ length $\times 3.5 \mathrm{~cm}$ depth; the surface of each face was polished using a gradation of grit sizes 400 and 600 grit silicon carbide and finished with $9 \mu \mathrm{m}$ aluminium oxide. Each block face was photographed under ultraviolet illumination with lamps oriented at $45^{\circ}$ angle using high-contrast, black-and-white Kodak T-Max 100 print film (the pores will appear black in the negative and white in prints from the negative). Each block was surrounded with a scale template cut from graph paper with 1-mm intervals marked.

\subsection{Image analysis procedure}

A total of 31 independent images representing the different slope angles were analysed with a Kontron ${ }^{\circledR}$ DEM-IPS ${ }^{\circledR}$ image analyser (Carl Zeiss). The area of block that was included in the analysis was $7.5 \mathrm{~cm}$ long by $1.5 \mathrm{~cm}$ deep. In order to assess changes in soil pore distribution, pore size and shape data were obtained from six successive regions of $2.5 \mathrm{~mm}$ depth each starting from the upper surface. Each block was analysed similarly maintaining same total areas for each region: The first region was defined parallel to the soil surface and each successive region was displaced $2.5 \mathrm{~mm}$ downward.

Soil pores were divided into three shape classes according to the ratio of pore area $(A)$ to the square of pore perimeter $(P)$ : values of $A / P^{2}$ greater than 0.04 were designated as round, those less than 0.04 and greater than 0.015 as irregular, and those less than 0.015 as elongate (Bouma et al., 1977; Pagliai et al., 1983). Pores were then subdivided into four size classes (50 to $<200,200$ to $<350,350$ to $<500$, and $\geq 500 \mu \mathrm{m})$. For round and irregular pores this subdivision was according to the equivalent pore diameter, $2(A / \pi)^{0.5}$, and for elongate pores according to pore width, $0.25\left[P-\left(P^{2}-16 A\right)\right]^{0.5}$ after similar procedures in Pagliai (1983), Pagliai et al. (1983), Valentin (1991), and Gimenez et al. (1992). Therefore, for each 2.5-mm layer, measures of the total pore area and frequency were obtained as well as data on pore area and frequency according to shape and size class.

\subsection{Statistical analysis}

Analysis of variance tests (presented below in Table 1) showed that there were no differences in any of the pore characteristics between slopes, so the values from separate slopes were grouped together into a single data set, and the results represent the means of 31 values per depth layer.

The design is a factorial experiment with two factors, slope angle and depth, and three repeated 
Table 1

Mean square values for pore characteristics

\begin{tabular}{|c|c|c|c|c|c|c|c|}
\hline Source & $D f$ & $\begin{array}{l}\text { Area, } \\
\text { round }\end{array}$ & $\begin{array}{l}\text { Area, } \\
\text { irregular }\end{array}$ & $\begin{array}{l}\text { Area, } \\
\text { elongate }\end{array}$ & $\begin{array}{l}\text { Frequency, } \\
\text { round }\end{array}$ & $\begin{array}{l}\text { Frequency, } \\
\text { irregular }\end{array}$ & $\begin{array}{l}\text { Frequency, } \\
\text { elongate }\end{array}$ \\
\hline Slope & 4 & 0.18 & 1.11 & 6.12 & 48.39 & 1.46 & 0.49 \\
\hline Error (1) & 25 & 0.27 & 0.98 & $20.03^{\mathrm{a}}$ & $42.10^{\mathrm{b}}$ & 8.42 & $0.63^{\mathrm{b}}$ \\
\hline Initial pore area & 1 & 0.36 & 0.38 & $60.76^{\mathrm{b}}$ & $85.69^{\mathrm{b}}$ & 5.17 & 0.04 \\
\hline Error (2) & 25 & 0.09 & 0.32 & 6.68 & 14.03 & 2.81 & 0.21 \\
\hline Depth & 2 & $9.15^{\mathrm{a}}$ & $8.32^{\mathrm{a}}$ & $565.78^{\mathrm{a}}$ & $1359.91^{\mathrm{a}}$ & $136.26^{\mathrm{a}}$ & $8.69^{\mathrm{a}}$ \\
\hline Depth $\times$ slope & 8 & 0.16 & 1.53 & 8.40 & 11.39 & 6.60 & 0.67 \\
\hline Error (3) & 52 & 0.17 & 1.03 & 6.78 & 22.29 & 4.98 & 0.36 \\
\hline $\begin{array}{l}\text { Depth } \times \text { initial } \\
\text { pore area }\end{array}$ & 2 & $0.90^{\mathrm{b}}$ & 3.81 & 14.23 & $107.38^{b}$ & $21.78^{\mathrm{b}}$ & 0.45 \\
\hline Error (4) & 50 & 0.19 & 0.91 & 6.48 & 18.89 & 4.30 & 0.36 \\
\hline
\end{tabular}

Error (1) is the residual for testing the slope term; error (2) is the residual for testing the initial pore area term; error (3) is the residual for testing both depth and the depth $\times$ slope interaction; error (4) is the residual for testing the depth $\times$ initial pore area interaction.

${ }^{a}$ Significant at the 0.001 level.

${ }^{\mathrm{b}}$ Significant at the 0.05 level.

measures of depth (top three layers) per sample for 31 samples. Only the top three layers (depth $0-7.5$ $\mathrm{mm}$ ) were included in the statistical test for two reasons. The first is that changes in porosity were most evident in these layers, as will be described in detail below. The second is that the initial porosity created during the packing of the trays may have affected the pore characteristics of the subsequent disrupted layer, so the areas of the lower three layers (depth $7.5-15 \mathrm{~mm}$ ) were averaged to create a covariate called «initial pore area», which was considered representative of the mean pore area of the sample prior to rainfall. The initial pore area is an index of initial bulk density. In all, six response variables (area and frequency for each of the three pore shapesround, irregular, and elongate) and one covariate (initial pore area) describing the pore characteristics were included.

The test used was a least-squares analysis of variance $F$ test. For each of the six variables and one covariate listed above, several null hypotheses were tested. These can be summarized as follows. There were no differences in pore characteristics according to slope angle or initial pore area between samples: rejection of these hypotheses would indicate that slope or initial pore area affected the pore character-

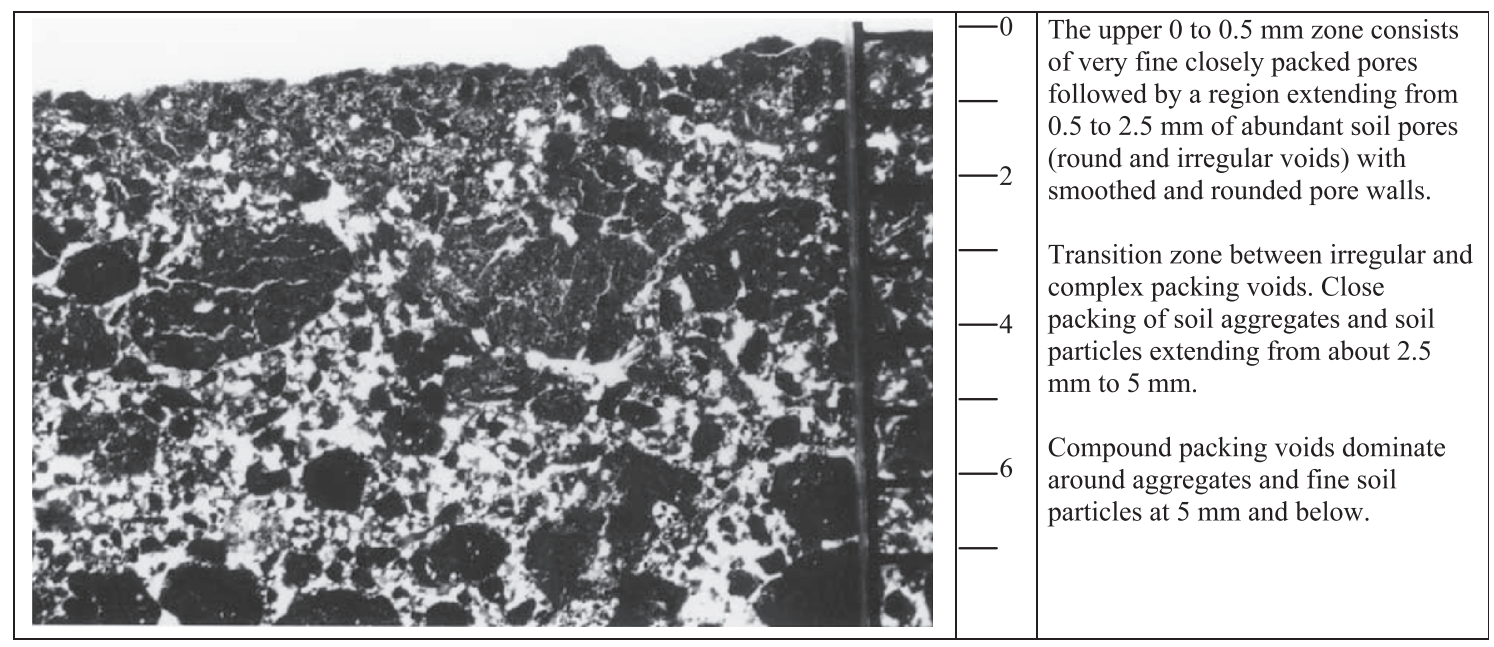

Fig. 1. Image showing the top $8 \mathrm{~mm}$ of soil (scale is in $\mathrm{mm}$ ). Pores are white and aggregates are black. 


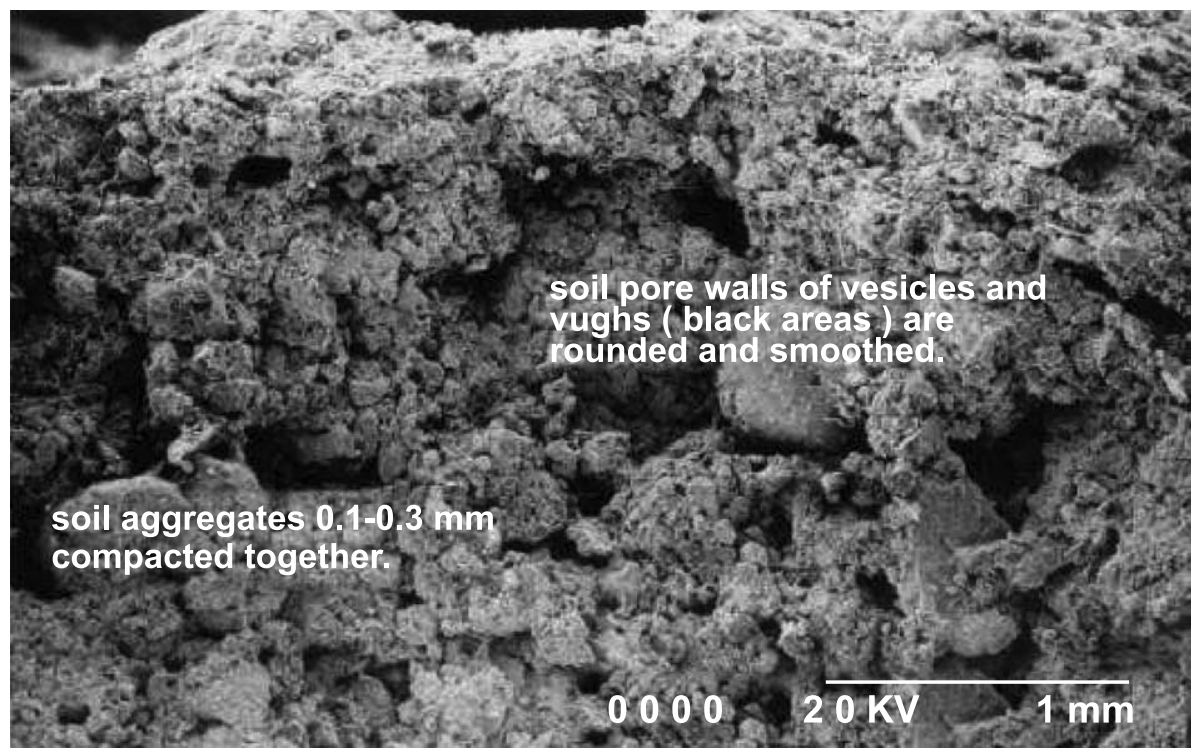

Fig. 2. Scanning electron image of upper dense crust layer.

istics, respectively. There were no differences in pore characteristics according to depth or a depth $\times$ slope interaction within a sample (since three depth measurements were performed on each sample, this test used repeated measures); rejection of this hypothesis would indicate that pore characteristics changed with depth or that certain depths reacted differently according to slope. Finally, initial pore area did not affect pore characteristics for some depths differently from others; rejection of this null hypothesis would indicate that some depths were affected differently by initial pore area than others.

\section{Results}

The results are organised in three sections: visual interpretation of images, statistical analysis of pore characteristics, and detailed description of pore characteristics. Characteristics of pores can be described by both their area and their frequency. The area of pores reflects the absolute value of porosity within each layer and is useful in showing changes in area with depth. The frequency of pores is the total number of pores within each layer. For each of these variables, pores are described according to the shape and size classes described above.

\subsection{Image descriptions}

The upper crust materials in the 0 to approximately $0.5 \mathrm{~mm}$ region consist of the compacted layer of soil particles and small aggregates less than $0.1 \mathrm{~mm}$

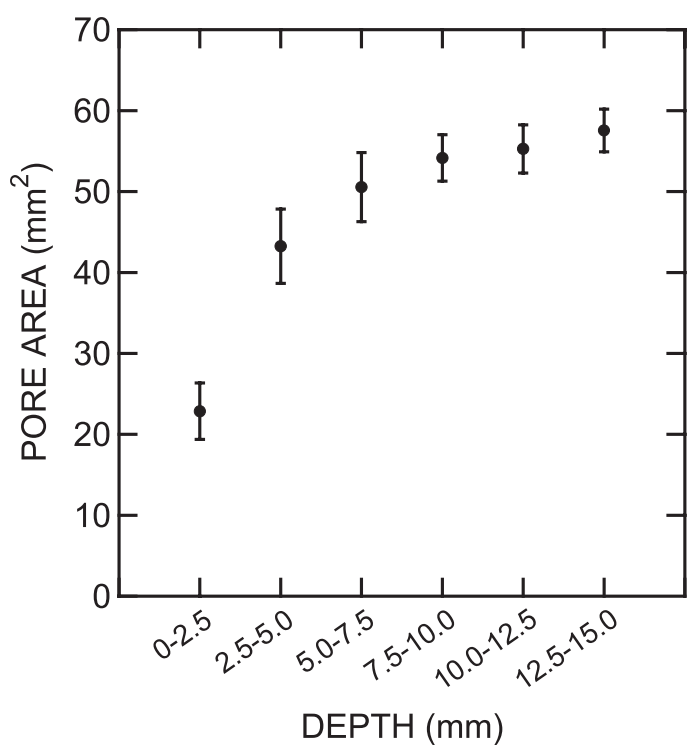

Fig. 3. Changes in total pore area (all shapes and size classes combined) with depth. Error bars are 95\% confidence intervals. 
a) $0-2.5 \mathrm{~mm}$

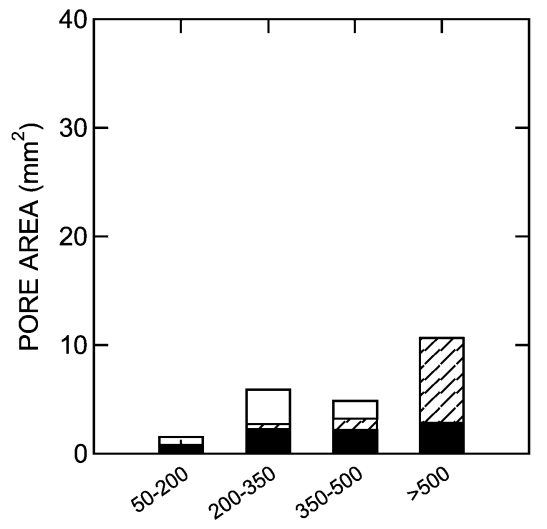

PORE SIZE $(\mu \mathrm{m})$

c) $5.0-7.5 \mathrm{~mm}$

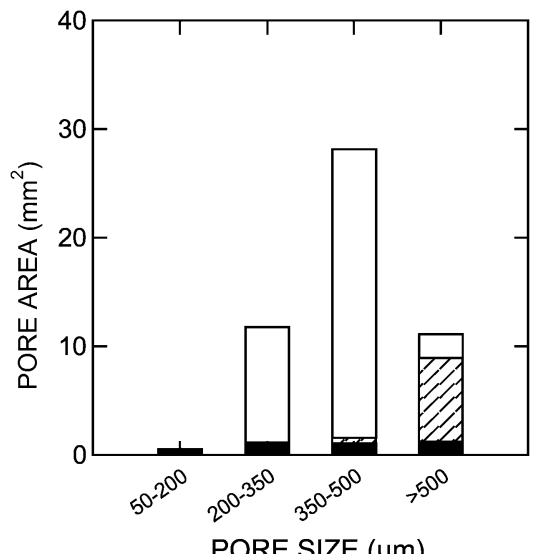

PORE SIZE $(\mu \mathrm{m})$

e) $10.0-12.5 \mathrm{~mm}$

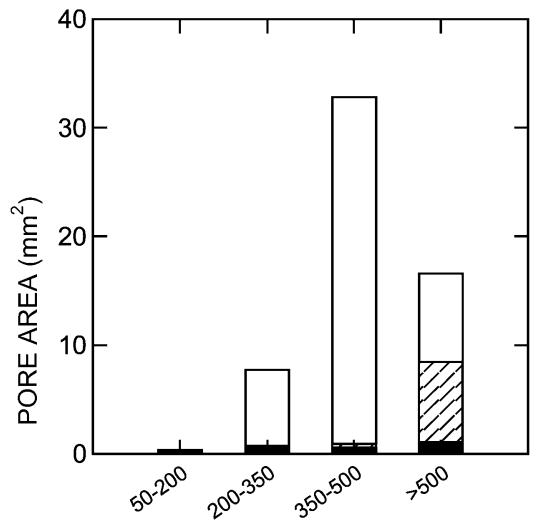

PORE SIZE $(\mu \mathrm{m})$ b) $2.5-5.0 \mathrm{~mm}$

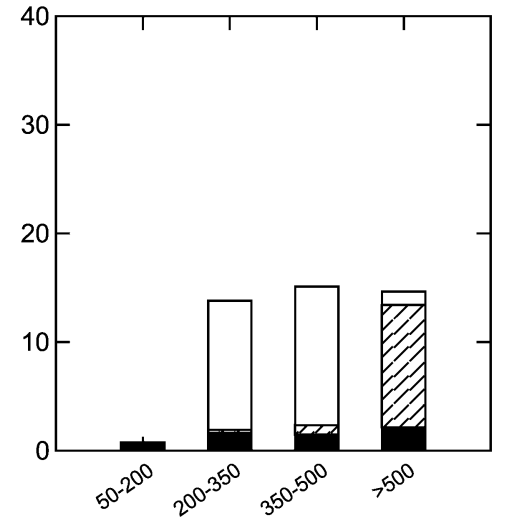

PORE SIZE $(\mu \mathrm{m})$

d) $7.5-10.0 \mathrm{~mm}$

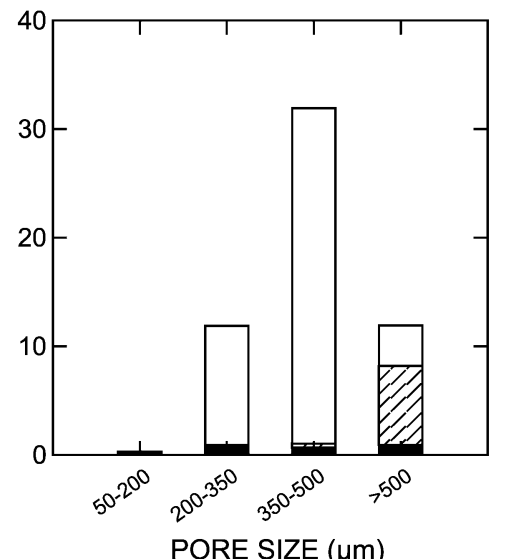

ROUND

$\triangle$ IRREGULAR

$\square$ ELONGATE
- ROUND

च IRREGULAR

$\square$ ELONGATE
PORE SIZE $(\mu \mathrm{m})$

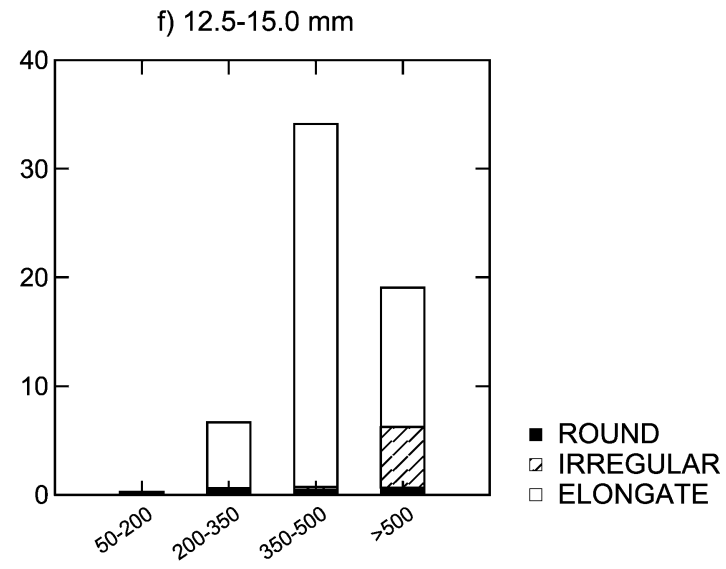

Fig. 4. Pore area according to pore shape and size class for each depth layer. Total pore frequency (all shapes and size classes combined) according to depth layer. 
(Fig. 1). Below this region in the lower crust $(0.5-2.5$ $\mathrm{mm}$ ), soil aggregates increase in size to values ranging approximately from 0.1 to $0.3 \mathrm{~mm}$. This area is characterized by abundant irregular voids and round pores (perhaps vesicles) that have smoothed pore walls. These distinctive pores occur across the entire sample and are aligned with the upper crusting zone forming a boundary with the lower soil materials. Within the upper and lower crusting zones, the soil materials have a rough appearance of close packing as observed in Fig. 2. The crust appears to have formed as a result of soil particle reorganization through break-up of the larger rounded soil aggregates (1-2 $\mathrm{mm}$ size) that characterized the experimental packing material. The redistributed soil particles have infilled around the soil aggregates to form a compacted layer with the finer materials possibly being sorted by runoff to form the cap upon drying. Further compaction of the upper soil materials likely occurred as the soil material dried out and materials linked in close proximity to each other forming a dense mass.

Below this upper dense crust, at depths ranging approximately from 2.5 to $5.0 \mathrm{~mm}$., there appears to be a transition zone. This zone represents a change from the predominantly round and irregular voids to a complex packing structure of the fine materials and soil aggregates of the experimental packing materials. There is a closer packing of the soil materials within this transition zone. The morphology of the underlying soil material is characterized by a complex structure with the finer materials organized between larger rounded aggregates $(1-2.0 \mathrm{~mm})$. This packing produces a very interconnected system of soil pores where pore areas for larger soil pore sizes are substantially increased.

\subsection{Statistical analysis}

In the analysis of variance presented in Table 1, the model includes slope and depth as main effects, the slope $\times$ depth interaction, the initial pore area covariate, and the slope $\times$ initial pore area and depth $\times$ iniinitial pore area interactions. The slope $\times$ initial pore area interaction was tested for each variable and depth, and it was found to be significant for only one (areairreg., depth $=2.5-5.0 \mathrm{~mm}$ ) of the 18 possible combinations of depth and pore characteristic (3 depths, 6 pore characteristics), and since one would expect at least one to be significant due to random chance at the 0.05 level ( 1 in 20), it was ignored.

Table 1 presents the mean square value of each of the response variables according to the independent variables tested. Values marked with ${ }^{\mathrm{a}}$ are significant at the $<0.05$ level and ${ }^{b}$ at the $<0.001$. Neither slope nor slope $\times$ depth are significant for any of the variables. This indicates that for the structural crusts in this study, slope did not affect the pore characteristics in the sealed layer, nor did it have any effect on the depth of the affected layer for the range of slopes observed.

The single most important variable is depth and changes in porosity with depth in the top three layers are statistically significant for all of the pore traits considered. These changes are described systematically below.

The initial pore area was significant as a main effect for five of the nine variables. When significant, it tended to have a positive relationship with elongate pores and negative with round and irregular ones. There was therefore a greater proportion of elongate pores with greater initial porosity. The interaction of depth $\times$ initial pore area indicates that the effect was not consistent for all depths. When considering individual depths (layer by layer), the covariate was not

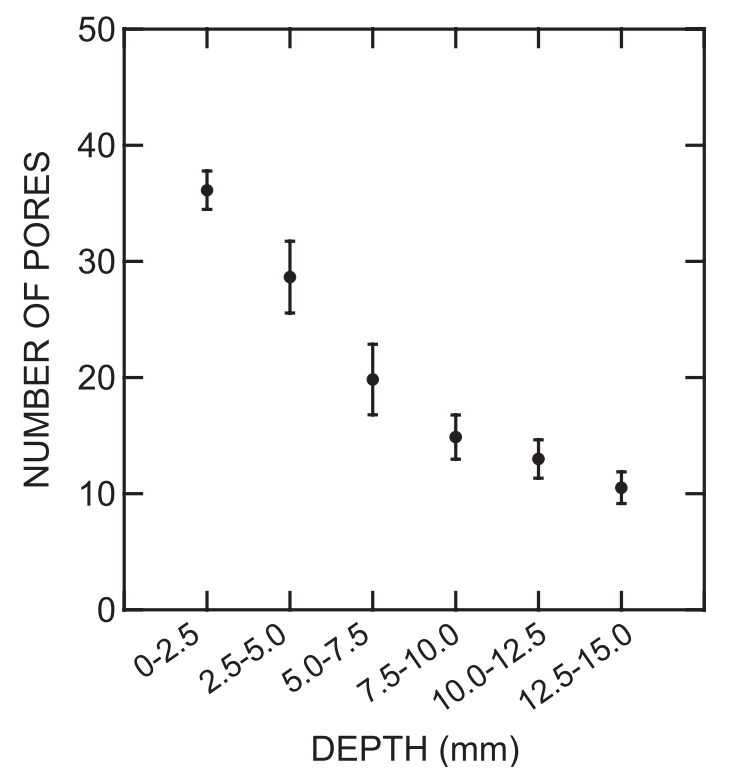

Fig. 5. Number of pores according to shape and size classes for each depth layer (error bars are 95\% confidence intervals). 

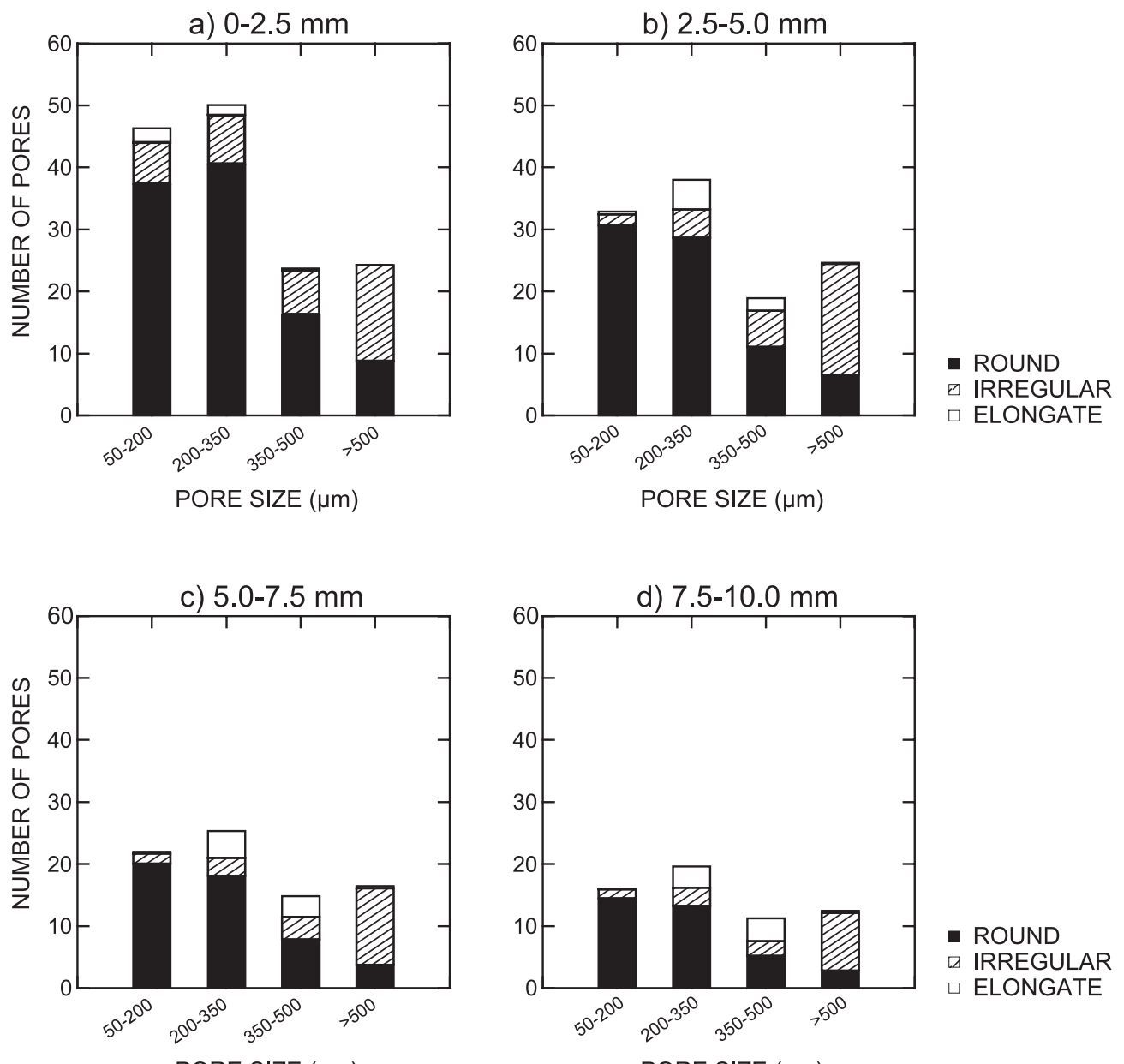

PORE SIZE $(\mu \mathrm{m})$
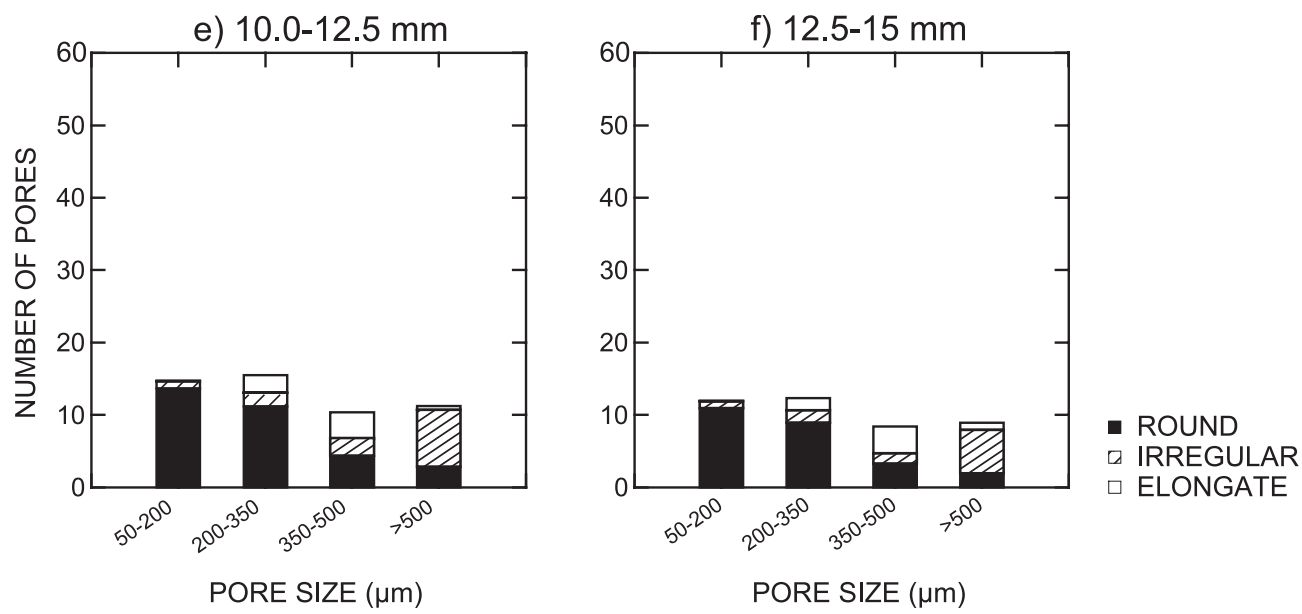

Fig. 6. Number of pores according to pore shape and size class for each depth layer. 
significant at the 0.05 level in the $0-2.5$ and $2.5-5.0$ $\mathrm{mm}$ layers for any of the nine pore characteristics. It was significant for six of the nine in the $5.0-7.5 \mathrm{~mm}$ layer. This indicates that the two upper layers were insensitive to the initial conditions because of the magnitude of the change brought about by the sealing processes. The third layer $(5.0-7.5 \mathrm{~mm})$ was less altered than the upper two layers and remained sensitive to initial porosity.

\subsection{Pore area}

Fig. 3 shows absolute pore area for each layer with all pore types and size classes combined. The increase is non-linear $\left(y=20.16 x^{0.424}, r^{2}=0.89\right)$ : The greatest change in porosity occurs in the top $5 \mathrm{~mm}$, and there is a smaller loss in porosity between 5 and $10 \mathrm{~mm}$ of depth; the change in porosity appears negligible beyond $10 \mathrm{~mm}$.

The distributions of pores according to type and size class for each layer are shown in Fig. 4 where total area for each size class is represented by the height of the bar. Each size class is subdivided according to pore shape. Porosity for all shapes and sizes is severely reduced in the upper $2.5 \mathrm{~mm}$. Total porosity increases greatly in the first three layers down to a depth of $7.5 \mathrm{~mm}$ and then only very slightly in the 7.5-10.0 mm depth; similarly, the distribution of porosity according to shape and size changes little beyond $10 \mathrm{~mm}$ and only slightly between the 5.0-7.5 and 7.5-10.0 mm layers.

The only exception is the smallest size class (50$200 \mu \mathrm{m})$, which is the only one to show a slight increase in the topmost layer $(0-2.5 \mathrm{~mm})$. Pores smaller than $500 \mu \mathrm{m}$ are somewhat reduced in the $2.5-5.0 \mathrm{~mm}$ layer. Total area for pores $>500 \mu \mathrm{m}$ does not appear to change beyond $2.5 \mathrm{~mm}$. The most important changes occur in the intermediate pore sizes and especially in the $350-500 \mu \mathrm{m}$ range where most of the decrease in total pore area occurs.

Round pores make up a relatively large proportion of the total porosity within the $0-2.5 \mathrm{~mm}$ severely disrupted layer, and their relative importance diminishes with depth. Irregular pores are also comparatively important in these layers, though the trend is much less marked than for round pores. Elongate pores follow an opposite trend to round pores, they increase in area with depth, especially in the $350-500$ $\mu \mathrm{m}$ size class. The only pores which increase significantly beyond $7.5 \mathrm{~mm}$ depth are the $>500 \mu \mathrm{m}$ elongate pores. Elongate pores represent the dominant pore shape, particularly in the intermediate-sized pores. Crusting therefore affects not only total porosity but the distribution of pores according to both type and shape as well. Before discussing the significance of this, changes in pore frequency (number of pores) for each layer will be presented.

\section{Pore frequency}

Intuitively, a loss in porosity is generally associated with a loss in the number of pores; however, the overall tendency in the number of pores is the inverse of the trend in porosity: the surface disrupted layer has the greatest number of pores, and frequency of pores decreases with depth (Fig. 5). Major changes occur in the top $7.5 \mathrm{~mm}$, with smaller changes down to $15 \mathrm{~mm}$.

Fig. 6 shows that round pores are concentrated in smaller size classes (50-200 and 200-350 $\mu \mathrm{m}$ ), especially in the disrupted surface layers where they are particularly numerous. Elongate pores are relatively few in number, even though they account for a major portion of the area; they tend to be found in the intermediate and large size classes where a few pores can account for the same area as several pores in the smaller classes. The method for size classifying these pores is different than for the other two shapes, so within a size class, a few pores account for more area than similarly sized round and irregular pores.

\section{Discussion}

The characteristics described above are for a single soil, but based on a literature review which included several soil types, Mualem et al. (1990) correctly predicted a similar overall trend in total porosity (or bulk density), so it is likely that trends observed here are also true for most structural crusts, even though the depth affected and rate of change with depth would vary from one soil type and context to another.

Similarly to the findings of others (Panini et al., 1997) elongate pores in the intermediate size classes $(200-500 \mu \mathrm{m})$ account for much of the porosity in the 
soil and are the most sensitive to surface crusting. Crusting due to the transfer of kinetic energy of falling raindrops to the soil surface both fragments and compacts aggregates. Aggregate breakdown products fill the voids between aggregates in the upper layer to form a dense layer of low porosity.

This study has shown that intermediate and large irregular and elongate pores are broken up into smaller round pores. Vesicles due to trapped air are also found in the upper dense layer (Valentin, 1991). Contrary to what would have been expected from total porosity data alone, the number of pores in the disrupted layer actually increases. Round pores make up a larger proportion of total porosity in the disrupted layer where the porosity is concentrated in more numerous, but smaller pores. The relative increase in small round pores in the disrupted layer can only be detected when distinguishing between the crust and subsoil layers, rather than measuring pores over a larger depth (Borselli et al., 1996; Panini et al., 1997; Uson and Poch, 2000), since their absolute area is small compared to other pores in the subsoil.

Water flow is extremely sensitive to pore diameter, as is known from Poiseuille's law, so the changes in porosity described above have a large impact on hydraulic conductivity. It is strongly reduced in the disrupted layer not only because of the lower total porosity, but also because of the change in distribution of pore shapes and size classes since round pores are less effective in transmitting water than irregular and elongate pores (Valentin, 1991). These changes have repercussions for infiltration modelling. Analytical approaches to crust infiltration modelling are generally based on modified versions of the Green and Ampt (1911) equation (Ahuja and Ross, 1983; Brakensiek and Rawls, 1983; Hillel and Gardner, 1970), and numerical approaches are based on the general flow equation adapted for layered soils (Aboujaoudé et al., 1991; Bristow et al., 1995). Both approaches require estimates of crust thickness and hydraulic conductivity.

The results indicate an exponential decrease in porosity and a change in pore type distribution near the surface. Although there is no distinct limit separating the crust from the subsoil, the pore morphology data suggest that a thickness of $5 \mathrm{~mm}$ is a reasonable approximation. However, the hydraulic conductivity will vary greatly even within the crusted zone since the upper $2.5 \mathrm{~mm}$ has a pore area less than half the $2.5-5 \mathrm{~mm}$ depth and a greater proportion of round pores. It is therefore likely that the hydraulic conductivity is significantly lower in this upper layer. Obtaining hydraulic parameters directly from pore micromorphology would require a three-dimensional view of the pore network, and more particularly of pore connectivity. This is beyond the scope of this paper, but the data available can be useful in estimating hydraulic parameters for infiltration modelling.

The crust zone is clearly present in the top $5 \mathrm{~mm}$ and has a transitional zone ranging from about 7.5 to $10 \mathrm{~mm}$, but the limiting zone for infiltration is probably confined to the upper $1-2.5 \mathrm{~mm}$. Using values for the $20.5 \%$ slope (Fox et al., 1997) of infiltration rate $(q)$ of $0.75 \mathrm{~cm} \mathrm{~h}^{-1}$ and pressure head (h) at $1 \mathrm{~cm}$ depth of $-12 \mathrm{~cm}$, it is possible to solve the Darcy equation, $q=-K(h / z)$, for hydraulic conductivity $(K)$ for a specified crust thickness $(z)$. For $z$ equal to 0.25 and $0.5 \mathrm{~cm}, K$ equals 0.016 and 0.031 $\mathrm{cm} \mathrm{h}^{-1}$, respectively. The difficulty in measuring crust hydraulic conductivity and estimating a realistic crust thickness can be circumscribed somewhat by combining the two parameters into a single term, hydraulic resistance $(R)$ (Hillel and Gardner, 1969). Hydraulic resistance is the result of the ratio of crust thickness to crust hydraulic conductivity and is equal to $16 \mathrm{~h}$ for the example just presented.

\section{Conclusion}

Modelling infiltration in surface crusted soils requires estimates of hydraulic parameters for the disrupted layer. Image analysis of impregnated blocks provides a quantitative description of changes in pore characteristics. As expected, total porosity was most affected near the soil surface and increased exponentially with depth. No distinct boundary between crust and undisturbed underlying soil could be identified, but pore characteristics showed that crusting was most intense in the upper $5 \mathrm{~mm}$ and negligible beyond 10 $\mathrm{mm}$. Intermediate-sized elongate pores were the most sensitive to crusting. The trend in pore frequency was roughly inversely proportional to pore area as elongate and irregular pores were broken into smaller round pores under the compacting effect of raindrop impact. The frequently used crust thickness of $5 \mathrm{~mm}$ for 
infiltration modelling in structural crusts represents a realistic approximation since it includes the most disrupted zone, even though a thinner upper layer of $1-2 \mathrm{~mm}$ probably has more physical significance.

\section{Acknowledgements}

The research was supported by an operating grant to R.B. Bryan from the Natural Sciences and Engineering Research Council, Canada, which is gratefully acknowledged.

\section{References}

Aboujaoudé, A., Belleudy, P., Vauclin, M., 1991. A numerical study of infiltration through crusted soils: flat and other surface configurations. Soil Technology 4, 1-18.

Agassi, M., Morin, J., Shainberg, I., 1985. Effect of raindrop impact energy and water salinity on infiltration rates of sodic soils. Soil Science Society of America Journal 49, 186-190.

Ahuja, L.R., Ross, J.D., 1983. A new Green Ampt type model for infiltration through a surface seal permitting transient parameters below the seal. Proceedings of the National Conference on Advances in Infiltration, vol. 11-83. American Society of Agricultural Engineers Publication, pp. 147-162.

Beckmann, G., Smith, K., 1974. Micromorphological changes in surface soils following wetting, drying, and trampling. Soil Microscopy, Proceedings of the 4th International Working Meeting on Soil Micromorphology, pp. 832-845.

Boiffin, J., 1985. Stages and time-dependency of soil crusting insitu. International Symposium on the Assessment of Soil Surface Sealing and Crusting, Ghent, Belgium, pp. 91-98.

Boiffin, J., Bresson, L.M., 1987. In: Fedoroff, N., Bresson, L.M., Courty, M. (Eds.), Dynamique de Formation des Croutes Superficielles: Apport de l'analyse Microscopique. Micromorphologie des Sols, Paris, pp. 393-399.

Borselli, L., Carnicelli, S., Ferrari, G.A., Pagliai, M., Lucamante, G., 1996. Effects of gypsum on hydrological, mechanical and porosity properties of a kaolinitic crusting soil. Soil Technology 9, 39-54.

Bouma, J., Jongerius, A., Boersma, O., Jager, A., Schoonderbeek, D., 1977. The function of different types of macropores during saturated flow through four swelling soil horizons. Soil Science Society of America Journal 41, 945-950.

Brakensiek, D.L., Rawls, W.L., 1983. Agricultural management effects on soil water process: Part II. Green-Ampt parameters for crusting soils. Transactions of the American Society of Agricultural Engineers 26, 1753-1757.

Bresson, L.M., Boiffin, J., 1990. Morphological characterization of soil crust development stages on an experimental field. Geoderma 47, 301-325.

Bristow, K.L., Cass, A., Smetten, K.R.J., Ross, P., 1995. Water entry into sealing, crusting, and hardsetting soil: a review and illustrative simulation study. Sealing, Crusting and Hardsetting Soils: Productivity and Conservation. Australian Society of Soil, pp. $183-203$.

Bryan, R.B., 1973. Surface crusts formed under simulated rainfall on Canadian soils. Consiglio Nazonale Delle Richerche Laboratorio per la Chimica del Terreno, Pisa, Conference 2.

Chen, Y., Tarchitzky, J., Brouwer, J., Morin, J., Banin, A., 1980. Scanning electron microscope observations on soil crusts and their formation. Soil Science 130, 49-55.

Collins, J., Smillie, G., Hussein, S., 1986. Laboratory studies of crust development in Irish and Iraqui soils: III. Micromorphological observations of artificially-formed crusts. Soil and Tillage Research 6, 337-350.

Duley, F., 1939. Surface factors affecting the rate of intake of water by soils. Proceedings-Soil Science Society of America 4, 60-64.

Eigel, J., Morre, I., 1983. Effect of rainfall energy on infiltration into a bare soil. Advances in Infiltration, vol. 11-83. American Society of Agricultural Engineers Publication, pp. 188-200.

Epstein, E., Grant, W.J., 1967. Soil losses and crust formation as related to some physical properties. Proceedings-Soil Science Society America 31, 547-550.

Evans, D., Buols, S., 1968. Micromorphological study of soil crusts. Proceedings-Soil Science Society America 32, 19-22.

Farrel, D., 1972. The effect of soil crusts on infiltration: the effect of aggregate size and depth of tillage on steady infiltration through crust-topped tilled soils. In: de Boodt, M. (Ed.), Proceedings Symposium on the Fundamentals of Soil Conditioning, pp. $1132-1149$.

Farres, P., 1978. The role of time and aggregate size in the crusting process. Earth Surface Processes 3, 243-254.

Fox, D.M., Bryan, R.B., 1999. The relationship of soil loss to slope gradient for interrill erosion. Catena 38, 211-222.

Fox, D.M., Le Bissonnais, Y., 1998. A process-based analysis of the influence of aggregate stability on surface crusting, infiltration, and interrill erosion. Soil Science Society of America Journal $62,717-724$.

Fox, C.A., Guertin, R., Dickson, E., Sweeney, S., Protz, R., Mermut, A.R., 1993. Micromorphological methodology for inorganic soils. In: Carter, M. (Ed.), Soil Sampling and Methods of Analysis. Lewis publishers, Ann Arbor, USA.

Fox, D.M., Bryan, R.B., Price, A.G., 1997. The influence of slope gradient on infiltration rate for interrill conditions. Geoderma $80,181-194$

Fox, D.M., Le Bissonnais, Y., Quétin, P., 1998. The implications of spatial variability in surface seal characteristics for infiltration in a mound and depression microtopography. Catena 32, 101-114.

Gimenez, D., Dirksen, C., Miedema, R., Eppink, L.A.A.J., Schoonderbeek, D., 1992. Surface sealing and hydraulic conductances under varying-intensity rains. Soil Science Society of America Journal 56, 234-242.

Hillel, D., Gardner, W., 1969. Steady infiltration into crust-topped profiles. Soil Science 108, 137-142.

Hillel, D., Gardner, W.R., 1970. Transient infiltration into crusttopped profiles. Soil Science 109, 149-153.

Kinnell, P., Cummings, D., 1993. Soil slope gradient interactions in erosion by rain-impacted flow. Transactions of the American Society of Agricultural Engineers 36, 381-387. 
Luk, S., Dubbin, W., Mermut, A.R., 1990. Fabric analysis of surface crusts developed under simulated rainfall on loess soils, China. In: Bryan, R.B. (Ed.), Catena Supplement. Soil Erosion, Experiments and Models, vol. 17, pp. 29-40.

McIntyre, D., 1958. Permeability measurements of soil crusts formed by raindrop impact. Soil Science $85,185-189$.

Morin, J., Benyamini, Y., 1977. Rainfall infiltration into bare soils. Water Resources Research 13, 813-817.

Moss, A., 1991. Rain-impact soil crust: 1. Formation on a granite derived soil. Australian Journal of Soil Research 29, 271-289.

Mualem, Y., Assouline, S., Rohdenburg, H., 1990. Rainfall induced soil seal (A): a critical review of observations and models. Catena 17, 185-203.

Norton, L., 1987. Micromorphological study of surface seals developed under simulated rainfall. Geoderma 40, 127-140.

Onofiok, O., Singer, M., 1984. Scanning electron microscope studies of surface crusts formed by simulated rainfall. Soil Science Society of America Journal 48, 1137-1143.

Pagliai, M., 1983. Caratterizzazione della porosita del terreno mediante l'analizzatore ottico-elettronica di immagine Quantimet 720. Agrochimica 27, 113-122.

Pagliai, M., 1987. Effects of different management practices on soil structure and surface crusting. In: Fedoroff, N., Bresson, L.M., Courty, M. (Eds.), Micromorphologie des Sols, Paris.

Pagliai, M., La Marca, M., Lucamante, G., 1983. Micromorphometric and micromorphological investigations of a clay loam soil in viticulture under zero and conventional tillage. Journal of Soil Science 34, 391-403.

Panini, T., Torri, D., Pellegrini, S., Pagliai, M., Salavador Sanchis, M.P., 1997. A theoretical approach to soil porosity and sealing development using simulated rainstorms. Catena 31, 199-218.

Poesen, J., Ingelm-Sanchez, F., Mucher, H., 1990. The hydrological response of soil surfaces to rainfall as affected by cover and position of rock fragments in the top layer. Earth Surface Processes and Landforms 15, 653-671.

Remley, P., Bradford, J., 1989. Relationship of soil crust morphology to inter-rill erosion parameters. Soil Science Society of America Journal 53, 1215-1221.

Tackett, J., Pearson, R., 1965. Some characteristics of soil crusts formed by simulated rainfall. Soil Science 99, 407-413.

Tarchitzky, J., Banin, A., Morin, J., Chen, Y., 1984. Nature, formation and effects of soil crusts formed by water drop impact. Geoderma 33, 135-155.

Uson, A., Poch, R.M., 2000. Effects of tillage and management practices on soil crust morphology under a Mediterranean environment. Soil and Tillage Research 54, 191-196.

Valentin, C., 1991. Surface crusting in two alluvial soils of northern Niger. Geoderma 48, 201-222.

West, L.T., Chiang, S.C., Norton, L.D., 1992. The morphology of surface crusts. In: Sumner, M.E., Stewart, B.A. (Eds.), Soil Crusting, Chemical and Physical Processes. Advances in Soil Science Lewis Publishers, USA, pp. 73-92. 